\title{
Design of a modern hydraulics laboratory for teaching and research
}

by

\author{
R. Mathieson, B.Sc., Ph.D., A.R.T.C., A.M.I.Mech.E., A.F.R.Ae.S. \\ and
}

J. Stebbings, B.Sc.(Eng.), A.M.I.C.E., A.M.I.Mun.E.

Mr Herbert Addison (Consultant) said that it could be agreed that in its own sphere this Paper was of unique interest. From \$ 7, in which one read about the features regarded as essential in the Manchester laboratory, it was easy to see that the list had been drawn up by experienced designers.

63. The stipulation for independent water supplies had necessarily brought into favour again the expedient of installing capacious overhead constant-level tanks. He had noticed, until recently, the contrary trend in favour of a multiplicity of pumps, each serving directly a particular piece of equipment. In the new Manchester laboratory, so thoroughly had the independent principle been applied that one observed from Fig. 4 that no less than 37 supply pipes each led directly from the appropriate tank.

64. With regard to the control of the water-level in the overhead tanks, it was revealing to notice from $\S 19$ that the overflow troughs were not normally in operation, which indicated great confidence in the operation of the automatic valves in the pump discharge line. But a closer study of the pumping and piping system showed that, so far as could be seen, not all the experimental units were protected against flow fluctuations. The main fiume, for example, was served directly by pumps 1 and 2 in Fig. 2, nor was any regulating device indicated; yet it would seem to be particularly necessary that the water-level in the flume stilling-bay should be kept steady for long periods within very close limits, especially when the calibration weigh-tank was in use.

65. Another piece of equipment which apparently could not profit from the constant-level system was the Kaplan turbine No. 7. According to $\$ 39$ of the Paper, this unit was directly fed from the variable-pitch propeller pump No. 6 . In carrying out the usual kinds of test on reaction turbines, the experimenters liked to keep the head completely steady and to vary the speed and discharge in some desired sequence. When a pump and a turbine were interconnected, however, their characteristics were such that head and flow-rate were liable to wander in a manner that no conventional type of control valve could master. It would be interesting to know whether the Authors had found a successful solution to this problem.

66. The Paper had shown how carefully each detail of the equipment of the laboratory had been foreseen, and $\mathrm{Mr}$ Addison looked forward to hearing how the laboratory was controlled and operated. Which department of the University accepted responsibility in this respect? To judge by the wealth and variety of the experimental equipment, a similar variety of students would profit. Some information about this had already been given. How was the onus of running and maintaining the new laboratory assigned to particular members of the academic staff? How were time-tables arranged so that the greatest number of undergraduates could have access to the laboratory? Although these might seem matters of administrative detail, they were of interest to all workers in this particular field.

* Proc. Instn civ. Engrs, vol. 29, December 1964, pp. 657-676. 
67. Mr Addison compared the laboratory with the Civil Engineering Hydraulics laboratory at Giza, ${ }^{2}$ near Cairo. He said that in this Cairo University building three separate laboratories were made available, allocated respectively to general fluid mechanics, civil engineering, and mechanical engineering. Rooms were provided for staff, for small tutorial classes, and so on, previous experience having shown how useful these could be. No doubt at Manchester similar facilities were available in buildings adjacent to the laboratory not shown in the Paper.

68. The civil engineering hydraulics laboratory at Giza showed resemblances to the layout described in the Paper, viz. the galleries, the hatches communicating with the underground sump, and the long flume intended for towing tests and perhaps for current meter rating.

69. According to the original intention, the Giza building, including laboratories on the ground floor and lecture rooms and offices on the upper floor, would constitute an autonomous department of the Faculty of Engineering. It would be maintained and administered by its own academic staff and would cater for whoever wished to attend, whether they were studying civil, mechanical, electrical, chemical or mining engineering. Perhaps the Authors of the Paper would care to suggest whether, in the conditions prevailing in Great Britain, such a plan would be likely to succeed here.

Mr L. E. Prosser (Director of Research, British Hydromechanics Research Association, Harlow) said that the Authors had shown an excellent layout of what might be called a classical type of laboratory in the direct evolution from Reynolds, and he had no comments to make on this aspect. It was obviously very well adapted and suited for the main function of teaching students, where perhaps the chief requirement was that one should be able to set up good demonstrations and experiments and be able to repeat them from year to year. This inevitably involved very considerable capital expenditure, but with relatively low subsequent running costs.

71. He wished to take the opportunity of mentioning the problem of providing an industrial research laboratory where very seldom was the same experiment performed twice, at least not in exactly the same form. There was also the problem of capital expenditure and the decision frequently had to be made as to whether it was best to invest limited funds in staff or equipment, and the tendency perhaps was to cut down on the equipment. The experience of the British Hydromechanics Research Association was that this was not necessarily a disadvantage. They had been operating for about 12 years in what, in effect, was a standard factory and had undertaken a very wide variety of hydraulic research experiments. Their general philosophy was as far as possible to provide each experiment with its own completely selfcontained equipment and facilities and when it was finished, to scrap it or cannibalize it. When one examined the facilities required in nearly all hydraulic experimental work, four basic features were required. Firstly a supply of water at a controlled head. This could be obtained very readily from individual pumps. Much of the prejudice against a pumped supply, compared with a constant head tank, may have arisen through the use of d.c. motors whose speed was sensitive to load and voltage variation. This no longer applied with induction motors as the grid frequency was usually very constant, and voltage and load variations had only a minor effect on motor speed.

72. Secondly, the flow had to be metered. Unless very high accuracy was required this could be done most conveniently by secondary standards in the form of orifices or weirs. If necessary these could be calibrated in specialized laboratories and the provision of large and elaborate volumetric or weigh tanks was unnecessary.

73. The third part of a hydraulic circuit was of course the experimental equipment being studied from whence the flow returned to the pump suction. This fourth stage could be a common sump for a majority of experiments, but there was no great advantage in providing a very large sump for this purpose. A relatively narrow channel down the middle of the laboratory would serve to collect the flow from a 
large number of separate experiments and had the advantage of not storing a large quantity of water. Water was extremely cheap, and at $3 s$. or $4 s$. per thousand gallons one could afford to throw the contents of a small system away quite frequently and renew with fresh water thus avoiding the necessity of having to provide elaborate filtration plant.

74. It was advantageous to make extensive use of wood both for models and for tanks. Resin-bonded plywood was waterproof and could be assembled quickly and cheaply into tanks of any shape, and these could easily be modified for future use. Even additional sumps could be made relatively cheaply, as it was comparatively easy to break up a concrete floor, and insert a tank if necessary.

75. He called attention to the desirable features of making hydraulic laboratories, particularly for industrial research, very flexible, and providing plenty of space. This was perhaps the main requirement. Height need not be very great although a gallery 12 or $15 \mathrm{ft}$ high over part of the floor was an advantage for cavitation experiments.

76. With regard to the use of constant head tanks, a colleague had pointed out to him that an effective constant level device was formed by an air-regulated syphon. Rather than using an extensive length of overflow weir, a relatively short length enclosed in a syphon which was designed to suck air when the upstream level was slightly depressed would maintain a nearly constant upstream head.

Dr D. M. McDowell (Consultant) said that he welcomed the Paper because the Manchester laboratory was one of the largest and most comprehensive to be built in Britain since World War II.

78. He had been concerned with the development of the hydraulics laboratory at the Queen's University, Belfast, which was completed in 1957, while working under Professor A. H. Naylor. The arrangement adopted by Professor Naylor was similar in many ways to that of the Manchester laboratory.

79. Although the five points listed in $\$ 7$ were borne in mind during the basic planning, the need for flexibility was a major factor in determining the layout of services in the laboratory. There were other ways in which the five objectives could be met. One would be to use individual pieces of equipment, each with its own individual supply. He had not worked out the cost of this but he was sure that it would be expensive when large numbers of students were working in a big laboratory and when facilities were required for handling large flow.

80. Another approach would be to provide an empty flat floor. This would give complete flexibility and the apparatus could be put anywhere. All that would be needed would be an overhead tank, a series of down pipes to convenient places, and portable sumps from which water could be returned. Use of a flat floor worked very well in a laboratory such as that of the Hydraulic Research Station, Wallingford, where flexibility was perhaps the paramount requirement. It did not work in a University where some pieces of equipment become semi-permanent and are very seldom moved. The return pipes from such equipment would cause congestion at floor level. Professor Naylor at Belfast had these points in mind when he was preparing the general layout of the laboratory and it was interesting to see that the conclusion he came to was in many ways very similar to the conclusion arrived at in Manchester.

81. Fig. 9 showed the general layout of pipe-work in the Belfast laboratory. Overhead supply tanks were provided, one of which was about $30 \mathrm{ft}$ above the main floor, while the other was placed at the highest available part of the building with a head of about $85 \mathrm{ft}$ above the main laboratory floor. The main feature of the laboratory, as at Manchester, was a completely clear main floor with water collecting channels below it. It could be seen that two ring mains were placed underneath the gallery to supply the main floor. Two pipes were installed above the gallery, one of which could be connected to either of the overhead tanks so that the independent overhead supplies were restricted to four. Dr McDowell did not think that this was a serious disadvantage because normally not more than four simultaneous experiments 


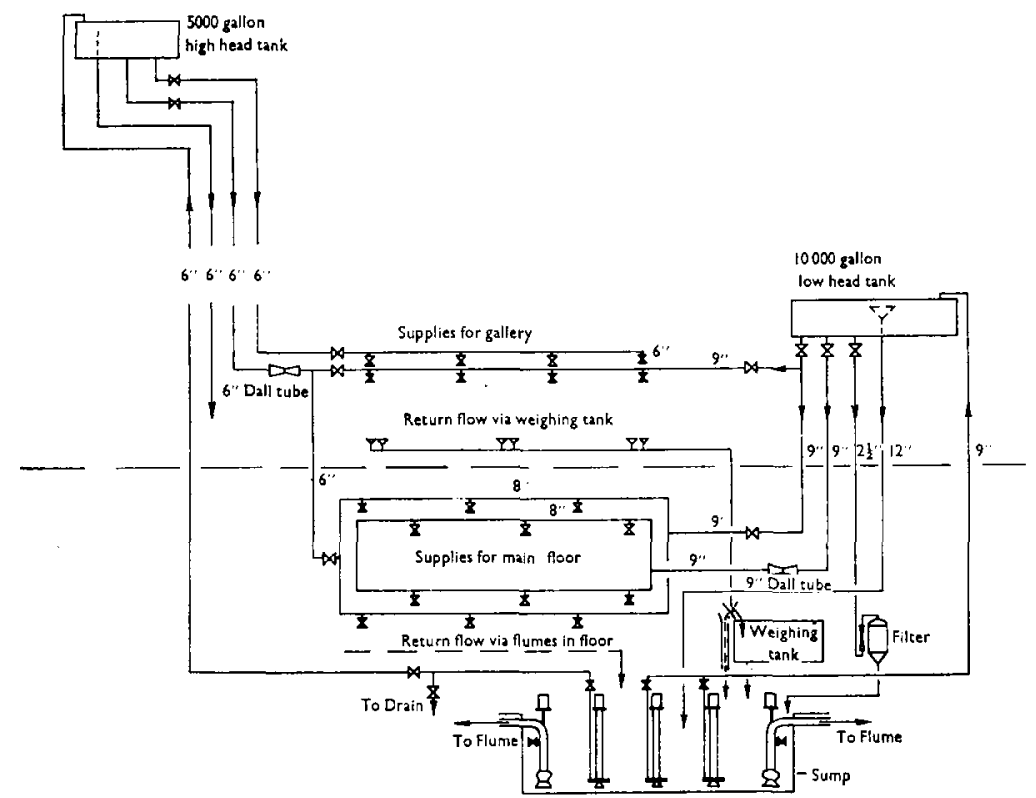

Fig. 9: General Layout OF PIPE WORK IN THE HydRaUlics Laboratory, QueEN'S UNIVERSITY, BELFAST

required an independent overhead supply. He wondered whether it was really necessary to have 37 separate supplies, particularly as some of them were of very small diameter. It seemed to be rather expensive, although it depended on the use to which the laboratory was to be put and the number of students who were expected to use it simultaneously. Could not the same effect be achieved by providing up to six supplies on the main floor and four on the gallery and using adaptors to bring the pipes down to the size required?

82. The arrangement for collecting water from the apparatus was by provision of channels under the main floor. Small channels, one foot square in section, were provided near each side of the Belfast laboratory, running along its full length. Portable apparatus could be sited anywhere along them and supplied with water from the nearest ring-main connexion.

83. The small channels each led into a large flume which ran along the centre of the laboratory under the main floor. This flume was about $100 \mathrm{ft}$ long, $5 \mathrm{ft}$ wide, and $3 \mathrm{ft} 6$ in. deep. Glass windows were inserted in the sides at two points with pits alongside from which the flow could be observed and photographed. Off-sets were also provided, as at Manchester, for three pieces of hydraulic machinery, used for student experiments. A flow of 10 cusec could be passed down the main flume from two low-head pumps which supplied the small side channels.

84. Weighing was used for primary flow measurement, as at Manchester, the capacity of the tank being about $10000 \mathrm{lb}$. The weighing machine was placed on the main floor and could be fed from the gallery. This had a disadvantage in that none of the flows on the main floor could be passed directly through the weighing tank. A series of secondary flow measuring devices was used such as notch tanks, which could be placed anywhere in the laboratory to collect flow and which could be calib- 
rated initially on the gallery. It would have been better, but very much more expensive, to make the sump much deeper so that the weighing machine could be sited below the main floor, as was done at Manchester. Although this would have been a better arrangement, he wondered whether the method of getting the flow into the weighing tank at Manchester would work particularly well. It appeared from the Paper that the flow had to pass through the main flume before entering the weighing tank. This meant that there was a large surface area interposed between the flow to be measured and the point where measurement was made. It seemed rather pointless to be able to measure to an accuracy of one part in 5000, when part of the flow to be measured might be detained temporarily in this large flume. Had the Authors an alternative way of getting the flow into the weighing tank or could they restrict the area of this large surface?

85. In Belfast also, steel pipes were used. The pipes were protected against corrosion by a method which had been used by the Hydromechanics Research Laboratory at East Kilbride. The pipes were sand-blasted or shot-blasted, internally treated with phosphoric acid and then given two coats of Detel Red chlorinated rubber paint. The water was also treated in a similar way to that at the East Kilbride laboratory by adding a coagulant when it first entered the laboratory. It was mixed in the low head tank and then passed through a filter into the sump after which it was treated with sodium nitrite to maintain its $\mathrm{pH}$ at the correct value. This was only partly successful. When Dr McDowell left Belfast in 1960, the laboratory had been used for only three years and in that time quite bad corrosion had occurred in some of the pipes. Those that suffered most were pipes that were seldom used: for example, on the gallery one of the main pipes was found to have retained a certain amount of air. Corrosion took place in this pipe particularly above the water level and it seemed clear that the treated water had not circulated freely through it. Was there any experience of that kind at Manchester and, if so, could the Authors suggest how it might be overcome?

Mr A. E. Seddon (Assistant Director, Hydraulics Research Station, Wallingford) said that the Paper was a very useful record of the new hydraulic laboratory facilities provided in Manchester and would be welcomed not only by those responsible for planning additional teaching facilities in the U.K. but also by planners abroad. There was at the present time an increasing number of overseas governments and organizations who were seeking advice on the best means of providing accommodation, equipment, and instruments for teaching and research in hydraulics. These people would welcome this Paper as an additional source of information, and he was sure that it would be of help to them.

87. Reference had been made by Dr McDowell to equipment and facilities which were available in Wallingford at the Hydraulics Research Station. The accommodation and the facilities provided in Manchester, and described by the Authors, differed in several important respects from those in Wallingford. This was due primarily to different functional requirements, locations, and site conditions. These differences were sufficiently pronounced to affect planning materially, as those who had been to Wallingford would know and as Mr McDowell implied in his comments. Whereas in Manchester facilities had to be provided for a very important teaching element as well as hydraulics research, those at Wallingford were required essentially for a wide range of basic and ad hoc research investigations in open channel hydraulics. Furthermore, provision was required in Manchester for experimental work on hydraulic machinery performance, a subject which was outside the scope of the work done at Wallingford.

88. The most striking effect of the differences in functional requirements was that whereas in Manchester vertical planning on a restricted site had been possible, at Wallingford effort had been concentrated on horizontal planning on a much larger site. Experiments with relatively large models of hydroelectric schemes, estuaries, 
and harbours required a large amount of floor space and a very large degree of flexibility in layout and services. In the early days of the Station some of the largest facilities, particularly wave basins for harbour studies, were built and operated in the open air, but now, with the exception of one area where meandering alluvial channels were studied, these facilities were all housed in permanent buildings.

89. There was a conflict at Wallingford between the need for flexibility and the convenience of having permanent tanks or basins available for studying particular river and tidal flow problems and hydroelectric schemes. The main hall, which had a much larger floor area than the laboratory at Manchester and in which much of the work of this kind was done, did not have a permanent floor surfacing so that the tanks, basins, and sumps required for a particular project could be easily excavated and purpose-built. Basically, an open space was available with complete flexibility in regard to providing equipment for a particular model. Water was often supplied by an individual unit supply, and permanent overhead tanks in the building were rarely

- used as header tanks for the models. The storage capacity in the main hall was of the order of 80000 gallons, but this was essentially a stand-by rather than a normal supply. Water was re-circulated in many cases, using either purpose-built reservoirs or channels incorporated in the permanent services within the building. As in Belfast, there was a system of return and waste channels round the periphery of the building, and these channels could be blocked and provided with any necessary throughways to give the required sump capacity and discharge to waste. Another important consideration was that almost invariably the required water supply was of low head as compared with the much greater range of head necessary in Manchester.

90. They had found at Wallingford that a ceiling height of the order of $25 \mathrm{ft}$ was necessary to give adequate height for overhead photography of large models and, in a large building such as the main hall, for transport of machinery and materials.

91. In $\S 44$ of the Paper the Authors mentioned the tilting sand flume which was provided in Manchester. Was any provision made for re-circulating the sediment in motion when the bed of the channel was of an erodible material and material was moving in suspension? Secondly, had any provision been made in the Department for further investigation of sediment transport in the larger channels that were now considered necessary in some quarters to make further progress in this field of research?

Mr B. Rydz (Messrs Binnie \& Partners) said that he wished to refer to the question of weigh calibration. Dr Mathieson's neighbour, Professor Francis, had opted for volumetric measurement on the grounds that one was more commonly concerned with volumetric relationships in a laboratory of this kind. He supposed that it was rather different at a place like East Kilbride where one was concerned with measurements relating to power machinery. He might be wrong in assuming that there was any great difference in cost and convenience between the two, but if volumetric equipment was simpler and cheaper, were there really any tests performed in a laboratory of this kind where the difference in accuracy between volumetric and weigh calibration was significant as compared with the accuracy of other measurements?

Mr J. A. Charlton (King's College) said that the Authors had given an especially interesting account of their new hydraulic laboratory, and in particular of the limits to which they had gone to achieve a reliable constant head supply to each specific piece of apparatus, and this was particularly impressive. As previous contributors had noted, no fewer than 37 down pipes had been used to achieve this. He would not argue with the fact that a constant head supply was undoubtedly required for research work, and no doubt this was the ultimate refinement for undergraduate tests. This ideal, however, was not always easy to achieve, and there was perhaps a number of people occupied at the present time in designing new laboratories in limited spaces where high head tank space and duct accommodation was at a premium and certainly 
would not accommodate 37 pipes. In a case like this he wondered if the Authors or anybody else had considered the use of constant pressure valves or constant pressure valves with a by-pass incorporated, to achieve a system giving a reasonably constant head supply for undergraduate tests. Such a system might compare very favourably with a cramped system using constant head tanks from a high source. The system he envisaged was a sump and a pump drawing water from it, and delivering water to the various pieces of apparatus through a constant head valve. Such valves, if correctly designed, or industrial ones, if these could be used, would achieve the same objective using considerably less space and perhaps costing less.

94. With regard to a point that $\mathrm{Mr}$ Prosser made about using an air regulated siphon as a constant head device in a constant head tank, he was sure that this would work extremely well, but it would have to be borne in mind, if this were used, that there would be a certain minimum overflow which would have to be maintained. Over and above this flow, when the siphon acted as an air regulated one, it would be possible within a very small structure to maintain a constant head supply to within very close tolerances.

Mr D. H. Simm (Kingston College of Technology) warned all those who intended to develop overhead tanks that, as Dr Mathieson had already said, a duct was required. In a recent expansion at Kingston College, the architects had provided a tank but had forgotten to provide a duct for the tank to be connected to the hydraulics laboratory!

96. It had been stated that approximately 100 civil and 100 mechanical engineering students were intended to use this laboratory. How many of these would in fact be using the laboratory at any one time? Dr McDowell had made this point but had not asked this specific question. Had the Authors any actual number in mind, and how many experiments did they expect to have running at one time?

97. Another important aspect in the design of a hydraulics laboratory was noise. At Kingston they had not been able to avoid it. The noise of falling water itself was often almost intolerable, and to add to this there was also the noise of the pumps required within the laboratory. Did the Authors think about this in the design at all?

98. Finally, he agreed with $\mathrm{Dr}$ McDowell that for civil engineering students the need was for more experience with pumps and less with turbines, and he felt this was an important factor in the design of a civil engineering hydraulics laboratory.

Mr M. J. Kenn (Imperial College, University of London) wrote that he had noted with interest and slight concern the formidable array of hydraulic machinery in the new Manchester laboratory. Doubtless, though, the Authors would be able to relieve this concern by reassuring him that no undergraduate would ever be required to run tests on more than a minute sample of this ironmongery, which included ten, or so, different impeller-pump or water-turbine test sets.

100. As amplified elsewhere ${ }^{3} \mathrm{Mr}$ Kenn believed that engineering students should be required to undertake fluid-mechanics laboratory tests but that these tests should be very carefully selected and devised.

101. He believed, for example, that the fundamental techniques for ascertaining machine characteristics could be largely appreciated from a single, well-devised test. Comparisons between experimentally-determined machine characteristics could, of course, be usefully and quickly made by each student, without each student actually undertaking the multiplicity of resemblant tests.

Dr R. Silvester (Senior Lecturer in Civil Engineering, The University of Western Australia) wrote that the Authors were to be commended for placing on permanent record the details of their newly constructed hydraulics laboratory. The design of such facilities absorbed considerable amounts of time and energy, which might be considered by research personnel as unproductive effort. But if the experience could be shared with workers in the same field many weeks of design work might be saved. 
Of all the laboratories in an engineering school, that for hydraulics had been the most fully integrated, due to the large volumes of water to be handled. The supply and metering had also to be matched to the experiments being served.

103. The Authors had presented their laboratory in the Simon Engineering building as a guide "to those who may be concerned with the design and equipment of the new hydraulics laboratories now being established as part of the expanded facilities for higher education'. It was with this contention that he would mainly take issue. He believed that the design was unsuitable for developing institutions because of its massiveness and inflexibility of layout. From a recent tour of the United States he had observed a trend away from pipe and channel supply systems, towards the individual pumping, metering, and sump unit. Such features permitted of ready change and obviated problems of dust and water stagnation.

104. If each new engineering school were faced with the cost that was embraced in the Manchester laboratory, the field of hydraulics would probably be omitted from civil engineering courses, or be taught without practical application. It was possible, however, to present verification of the theory in this field by means of much more modest equipment, with the advantage that students are not overpowered with a great display of horsepower. With regard to costs, it was difficult to correlate expenses of the various engineering departments, either through number of staff or students served, costs per building square or division between structure and equipment. He would be interested to see the overall cost of this laboratory, with as much further detail as the Authors could supply.

105. Size. The main sump appeared extremely large for the volumes of water to be absorbed at any one time. Its area was of the order of 1300 sq. $\mathrm{ft}$ so that even if the main flume was filled to capacity, the level of the sump would fall only $2 \mathrm{ft}$ out of the probable $5 \mathrm{ft}$ working depth. This large capacity had introduced difficulties in regard to filtration as noted by the Authors in $\S 13$.

106. Immensity not only applied to the reservoir system but also to the pumping energy. Considering, for example, the supply to the main flume, the water had to be raised from the sump, a matter of $6 \mathrm{ft}$ approximately, requiring perhaps $12 \mathrm{ft}$ of pumping head to cope with friction losses if a unit was placed conveniently. However, the water was raised to a pressure of $40 \mathrm{ft}$ by pump No. 1, or to $120 \mathrm{ft}$ through the high level tank by pump No. 38 (based on the normal discharge figures supplied). This implied a wastage of energy through valves or other dissipators of $27 \mathrm{hp}$ and $60 \mathrm{hp}$ respectively (calculated on water horsepower).

107. It was a fact that the useful time for teaching and research equipment throughout the year was relatively slight, but the provision for such losses involved extra capital and running costs that might be easily avoided. It might be contended that pump No. 1 was also available for turbine No. 5 , but here the discharge did not seem to match extremely well, since its $25 \mathrm{hp}$ output was served by a $40 \mathrm{hp}$ prime mover.

108. General water supply. The main supply to the laboratory was furnished through two constant head tanks, which in themselves appeared excessive for the demands made upon them. According to § 19, 'Under normal conditions the level in each tank is maintained within close limits at just under overflow level by a pneumatically-operated valve in the pump discharge line'. Dr Silvester would like 'normal conditions' to be specified more accurately, but he also could not understand the need for these valves when such long weir overflows were provided. If the valves were necessary for teaching or research purposes their presence should have permitted smaller constant head tanks. Even without their insertion it would appear that the maximum flow was discharged with only $\frac{1}{2}$ in. head over the weirs. Such close tolerances of pressure-head on experiments were not really demanded since the flow had to be controlled and metered at the consumption end and the main requirement was elimination of swift pressure changes. Assuming that an overall variation of 1 in, was permitted in the tanks (which appeared to be the case) the percentage change 
in head was $0.12 \%$ for the lower tank and $0.07 \%$ for the high tank, which were well below the value for turbulent fluctuations on entry to an experimental rig.

109. The 38 separate pipes from the constant head tanks would have a size commensurate with the probable demand, such that the maximum velocity was in the order of $5 \mathrm{ft} / \mathrm{sec}$. This would entail approximately $10 \%$ loss of the static pressure and when maximum demand was made by the experiment, the inlet pressure was at its minimum. Using the alternative of a pump on each unit, improved headdischarge characteristics would be available. The aim of the present system was to minimize interference from one experiment to the next, but this could have been achieved by the use of such individual pumping units, with perhaps greater flexibility of layout and certainly less running costs.

110. One of the features of laboratory classes was that all apparatus was not being used simultaneously. With perhaps six groups of students attending at any one time only a half, or a third, of the total units might be in use. In spite of this, a constant head tank must be operated at almost full capacity. Again, not all experiments were of the same duration and sometimes groups wished to return out of hours to complete, or repeat, a set of readings. In all these cases with the Manchester laboratory, a pumping unit of 50 to $100 \mathrm{hp}$ must be employed, no doubt with the compulsory attendance of a laboratory technician or staff member. How much simpler and economical it might be to throw a modest switch.

111. It was not necessary to have a pump for each experiment, since two experiments could be served which covered different stages of the one course, or different years of the course. Even apparatus with different supply characteristics could be attached to the one pump with the addition of a water-jet-pump unit. The use of this ejector-type combination had been suggested for a number of applications. ${ }^{1}$ In a laboratory where both high head-low discharge and low head-high discharge supplies were demanded a stock centrifugal pump could supply the former and also the latter by way of a mixing tube of suitable proportions. Used in this way the mechanical efficiency was in the order of $60 \%$ and pipe lengths for the majority of the discharge could be kept to a minimum.

112. Main fume. The main concrete flume was a feature of the laboratory. Dr Silvester wondered why the section $3 \mathrm{ft} 6 \mathrm{in} . \times 3 \mathrm{ft} 6$ in. was chosen, since it was smaller than the generally accepted size for standard calibration tests. The total length of $75 \mathrm{ft}$ appeared also to be quite modest for the use of a towing carriage, when approximately $30 \mathrm{ft}$ of it would be taken up with acceleration or deceleration. This length was partly dictated by the space allowed for the laboratory, but it would seem that the $20 \mathrm{ft}$ entry length and the weighing tank at the downstream end used up useful space. The former could perhaps have been made deeper with improvement in its energy dissipating qualities and the latter placed to one side.

113. This was the first occasion that he had read of plate glass being used to line a concrete flume. He would be interested to learn how the glass was attached and what provision had been made for replacement of panels. Whilst terrazzo may suffer the disabilities noted, he had found that a smooth strong concrete mortar sufficed in the many flumes he had inspected.

114. Flexibility. One further criterion should be added to those listed by the Authors for design of hydraulic laboratories, namely: $(f)$ design and connexion of apparatus to provide the greatest flexibility for additions and modifications. This had already been mentioned in respect of pumps and sumps for individual experiments. Besides the advantages stated above, the use of isolated sumps reduced the dust menace and also the corrosion factor since the unit was emptied as soon as the active period was completed for the year. Many such units could be made mobile so that they could be removed from working areas during the slack period.

115. In regard to measurement of large discharges the Authors stated in $\$ 11$ that they 'decided in favour of weight in preference to volume calibration'. Dr Silvester asked for elaboration on this choice, since the cost involved appeared to exceed, by 
several times, that of volume measurement. In the use of the latter, timing units had been developed which could be actuated by water contact with pointer gauges, so that an extremely accurate and swift means of measurement was available, with application to test-tubes or test-tanks. Commercial units were no doubt available for the electric supply conditions elsewhere in the world, but the writer had reported on a unit ${ }^{2}$ developed for the 50 cycle current available in Australia. These electronic counters had been made portable so that they could be attached to experiments as required, with pointer gauge settings to suit the specific discharge rates.

116. Even where a central distribution system was felt necessary, he might suggest an alternative to the constant head overflow tank. In the laboratory at the University of Western Australia he had contemplated the use of high level tanks in the roof of an adjoining building, but finally designed a pressure tank which could supply steady conditions at a number of pressure levels for a fraction of the cost. This unit was shown diagrammatically in Fig. 10 and its operation discussed elsewhere. ${ }^{4}$ By using air pressure and a floating spear valve, the head was maintained within 1 or $2 \%$ of the operating valve and all fluctuations in the system were moderated successfully. One further advantage of such a system was the modest space it occupied, so that it could be located in the centre of the laboratory. This resulted in shorter pipe connexions with concomitant savings in friction head.

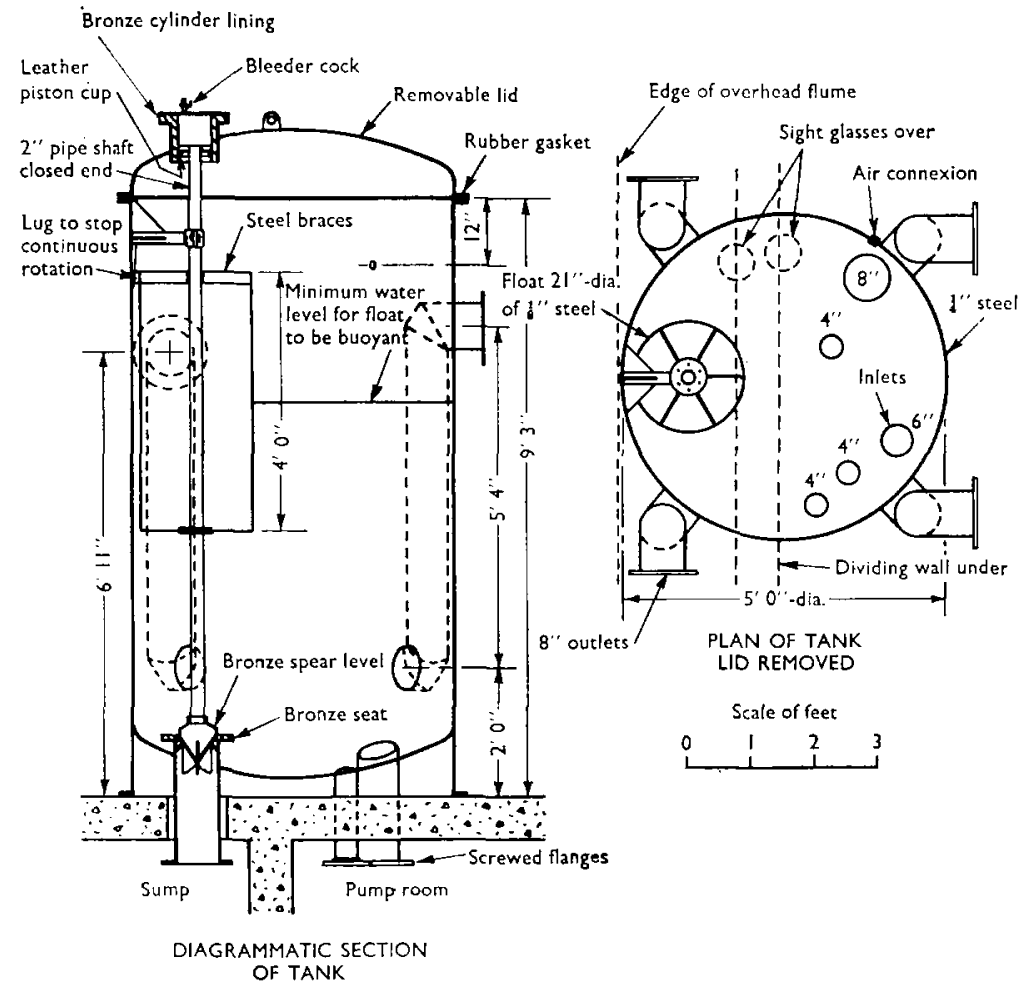

reproduced by permission of 'Engineering'

Fig. 10: Constant head tank INSTalled AT THE hydRaulics Laboratory, UNIVERSTTY OF WESTERN AUSTRALIA-MAX. PRESSURE, 45 LB/SQ. IN. 
The following contributions were received in writing:

Dr D. I. H. Barr (Senior Lecturer, Department of Civil Engineering, University of Strathclyde) wrote that he had had the privilege of being shown the new hydraulics laboratory at the University of Manchester by Dr Mathieson and Mr Stebbings. The new civil engineering hydraulics laboratory of the University of Strathclyde was of the same order of size as the Manchester laboratory and the former was now in the early stages of construction. The considerable differences in the two laboratories illustrated that two groups of people, while basing their design on much the same general requirements, could evolve quite dissimilar solutions. At Strathclyde each major piece of apparatus would in general be served by one or more independent basement sumps each with its own pump. This approach had been based on the past experience at Strathclyde where various studies had been undertaken involving, firstly, the bringing together of bodies of water of differing characteristics and, secondly, the use of large quantities of cheap local sand. Undoubtedly the Manchester and the Strathclyde laboratories were, and were intended to be, at different points of the spectrum of hydraulics laboratories, if that were taken as ranging from a mechanical engineering emphasis through normal open channel work to regime studies and coastal and estuarine engineering studies. However, it had at Strathclyde been found expedient to avoid interference between different pieces of apparatus by making them independent, even where pure water was being used in both cases. In general more would be spent on sumps and pumps at Strathclyde and less on pipework, when compared with Manchester.

118. It seemed to Dr Barr that in future years those at Strathclyde might well envy the ease of flow calibration available at Manchester, and the great stability of supply head, while those at Manchester might envy the flexibility available in the Strathclyde laboratory. It was intended in the latter case, for instance, to provide a hundred foot long basin for tidal model work, with a tide generator based on the pump and control gate principal. With an independent sump, the use of saline water in the basin would represent no hazard to other apparatus.

Mr F. A. Kilner (University of Cape Town) wrote that the publication of the Paper would be welcomed by those whose specialized task was the planning and operating of hydraulics laboratories. In the twenty years since the end of World War II, many new laboratories must have been designed and constructed, some for academic workers and others for scientific and industrial research, yet few descriptions of these enterprises are available to guide planners in this field. There were some exceptions, and as the Authors omitted any reference to previous publications of this type, $\mathrm{Mr}$ Kilner provided references 7, 8, and concerned respectively with university laboratories in Stockholm and an industrial laboratory in Kilmarnock.

120. There was no doubt that the essential design features listed by the Authors in $\$ 7,(a)$ to $(c)$, were vital, although opinions might well differ as to the relative importance of the items and also the most successful way to accomplish them.

121. Item (a) was usually achieved by a constant head tank in which the flow variations from a pumped supply, due to variations in both sump level and pump performance, were transmitted to the overflow rather than to the experimental equipment supplied by the tank. Ideally perhaps, each piece of apparatus should have its own constant head tank, but this was impractical for flows exceeding about $1 \mathrm{cusec}$, and this lead to the concept of a multiple outlet tank, where the overflow now had the additional duty of accepting the flow variations as the draw offs to several experiments were varied simultaneously.

122. The Manchester laboratory was based on this system, with two tanks, separate and at different elevations, having a total of 37 independent downpipes. With the overflow weirs provided, the maximum head variation was $\frac{1}{2}$ in. in an elevation to floor level of about $100 \mathrm{ft}$ (for the upper tank). As the flow from most laboratory 
outlets was related to the square root of the head available, the maximum flow variation was about $0.02 \%$, due to this source alone. Model tests of a multiple outlet tank of prototype capacity 20000 gallons carried out at Cape Town in connexion with a recently constructed laboratory showed that the variations in outflow caused by the opening of an adjacent outlet in the tank could be at least $0.25 \%$, caused presumably by the changing flow pattern within the tank itself. Thus it appeared that the provision of a considerable spillway length might be an unjustified refinement in a multiple outlet constant head tank.

123. The operation of the constant head tanks, as described in $\S 19$, appeared unconventional in that the high capacity overflow specifically installed as a constant head device was out of operation under normal conditions, and spill only occurred when the air supply to the pneumatically controlled valves failed. This procedure seemed to nullify the benefits of the long crested overflow, and if the response characteristics of automatic controls was under study, surely this should either be divorced from the basic water supply system, or more profitably the controls should be incorporated in the overflow pipes to maintain the overflow at a constant and economically low value.

124. The arrangement whereby 26 downpipes were connected individually to the same number of experiments, as outlined in $\$ 22$, was ideal, but presumably some economy could have been achieved by sharing a downpipe between several items of equipment, judiciously chosen so that their simultaneous use was rare.

125. Item (c), $\S 7$, concerning the flow measurement within the laboratory had been wisely solved by the use of gravimetric rather than volumetric methods, but the time required for steady conditions to be established in the supply flume might prove a real disadvantage in practice.

126. It might be appropriate to outline the development in the field of hydraulic engineering at the University of Cape Town. A new hydraulics laboratory was occupied during 1964 as part of a new building for the civil engineering department. The floor space available for hydraulics was $6000 \mathrm{sq}$. $\mathrm{ft}$, which was somewhat less than the area of the Manchester laboratory. A single constant head tank, in the form of an external water tower of 20000 gallons capacity, was used with ring main outlets of 8 and 12 in. diameter. All the pipe work, including bends, tees, and couplings, was in P.V.C., and thus corrosion was restricted to valves and pump casings. The floor channel layout was similar to the Manchester arrangement, and the sump capacity was 60000 gallons, although this included a $5 \mathrm{ft} \times 5 \mathrm{ft} \times 300 \mathrm{ft}$ towing and wave channel which could be separated from the main sump system when desired. The $300 \mathrm{ft}$ length was achieved by 'invading' other sections of the department, and for this reason the towing channel was covered with hinged covers throughout its length. All floor channels were covered with open type steel flooring, which permitted water to flow freely back into the sump system at any point without lifting the floor panels. No provision was made for calibration facilities other than a 2 ton mobile measuring platform, and for high flows, a novel system of discharge measurement was to be used.

127. A suitable flow was discharged down a pipe line containing the meter requiring calibration, and then the water supply to the tower was shut off. The (falling) water level in the tower and the indicating device for the meter were measured at suitable time intervals using two observers. The gradient of the tank volume vs. time curve showed the flow to be related to the corresponding meter reading. By adjusting to a new flow value and repeating the procedure, the full flow range of the calibration was obtained. This method, which could be described as an upstream volumetric calibration, had the advantages that any device may be calibrated in situ, the delay between successive readings was only the time required to refill the water tower, and the dual use of the constant head tank permitted a volumetric capacity which could hardly be contemplated within the laboratory. The method assumed, of course, 
that all other outflows (including leakage) were eliminated while the calibration was in progress.

128. He wished to express his gratitude to the Authors for the stimulus he had received from their Paper. Any further information the Authors could offer concerning the administration of the laboratory would be most interesting. He had in mind details of the laboratory utilization, for example the number and level of student hours per week for which the laboratory would be used, the numbers of technical and academic staff allocated to this section of the engineering faculty, as well as the annual grants available for continued expansion of the laboratory.

Professor A. H. Naylor (Department of Civil Engineering, Ahmadu Bello University, Northern Nigeria) wrote that the account of the new hydraulics laboratory was of particular value to those who were engaged in hydraulics laboratory design. Although many questions arose, they should not be taken as a lack of appreciation of the merits of the design.

130. No mention was made of provision for scale models of large area. This seemed particularly strange in the heritage of Reynolds and Gibson. Could no space be found?

131. With regard to the main flume, some description of the methods adopted or envisaged for towing models at constant speed and for wave-making would be of interest. The failure of the interstitial mortar of the terrazzo was possibly due to inevitable high water/cement ratio. Was granolithic concrete surface tested? Would not plate glass bedded on mortar have been cheaper than slate for the base and equally satisfactory? Interlocking extruded aluminium floor panels were used at Queen's University, Belfast, to cover the flume. They were very noisy and flexible to walk on and the surface groovings collected dirt like a scraper. With care, dust and dirt should be kept from getting through. They were expensive so that their justification depended on the importance of lightness and small stacking volume.

132. Would the Authors indicate the degree of accuracy attainable with intermittent weigh-batching?

133. With regard to the purification plant, if dosage was continuous there would be a steady accumulation of sodium sulphate in solution. Could the time between changes of water be given or was this arranged as a continuous process? It would be interesting to see if Detel proved satisfactory. One cause of corrosion trouble experienced at Queen's University, Belfast, was stagnant water in partially filled, infrequently used horizontal mains. It was desirable that such pipes should be laid at a gradient and drained when not in use, or alternatively accumulation of air prevented. The addition of sodium nitrite to the water as a corrosion inhibitor gave disappointing results. It was found better to have frequent changes of fresh water.

134. He noted that aeration of the water took place after filtration. While this was desirable in drinking water, was there any point in it here? Since dissolved oxygen was the cause of corrosion trouble, would not, in fact, one solution be to de-aerate the water? A possible way of doing this would be to use the siphon principle locating a closed large high-level tank at the crown of the siphon and maintaining it at high constant vacuum by an air pump. The large capacity would allow time for de-aeration. Such a solution, though, would possibly be too expensive. The protective measures adopted may suffice.

135. Some rough indication of the cost over and above that of normal university building would be helpful.

The Authors thanked the many contributors to the discussion for their interest in the Paper. It was noteworthy that they had expressed general agreement with the features listed in $\$ 7$ as essential in the design of a new laboratory; and many of the comments concerned the relative merits of the methods adopted at Manchester for 
achieving the desired objectives and alternative methods either proposed or already in use, in other laboratories.

137. Requirement 7(a), commented upon by $\mathrm{Mr}$ Addison and a number of subsequent contributors, raised the issue of the multiple pump versus the constant head tank with multiple pipe system, together with various modifications thereof. Thus a further explanation of the factors influencing the Authors' choice seemed appropriate.

138. It should be noted that the laboratory was originally designed for an ultimate yearly intake of 100 civil and 100 mechanical engineering students together with up to 15 postgraduate hydraulic engineering students. (The mechanical engineering students are also served by an extensive gas dynamics laboratory.)

139. The large number of students, a limited floor area, the trend in favour of project experiments instead of the conventional set type, and limited technician services, all led to a concept of flexibility not normally associated with hydraulics in the past. This approach was the normal one for light electrical engineering or electronics where current is supplied throughout the laboratory at various voltages and frequencies and with multi-socket outlets for the rapid and convenient connexion of experimental apparatus.

140. It was envisaged that most project students would be allocated a laboratory area and be able to connect their apparatus to a convenient tee from the high or low tank as appropriate. Flexible P.V.C. piping up to 3 in. diameter jubilee clipped enabled rapid connexion to be made without waiting for the installation and wiring of a pump. Even the fitting of rigid P.V.C. piping when necessary was not greatly time consuming. Orifice plate or venturi meters could be easily fitted into the supply pipes along the wall or under the gallery as required, giving adequate upstream and downstream 'straights' without absorbing much floor area or producing a jungle of criss-crossing pipelines.

141. On the same consideration Dr Silvester questioned the flexibility of the multiple pipe system adopted. The Authors did not agree that the laboratory was lacking in this respect. As mentioned in the Paper, a number of offshoots were separable from the sump and a few general purpose pumps were available, but from the operating experience to date, the technicians when left to choose, connected research apparatus to the already available tee connexions both for speed and for ease of fitting. Much of the equipment in the laboratory itself could easily be removed if desired; the main items of equipment which could be regarded as fixed were in two groups of machinery, one located over the deep sump and the other at offshoot No. 4. The main flume and weigh tanks were below floor level and being covered did not fall into the fixed-floor-occupying category.

142. Dr Silvester also considered the independent pipelines costly, but as suggested by Dr McDowell, this depended on the use to which the laboratory is put. The initial tank and piping costs were admittedly large, but if one considered the laboratory at full capacity with undergraduate experimental projects and postgraduate research apparatus fitted with individual pumps-to avoid interference with flows and give freedom of operation at any time-the cost of pumps together with the cost of their installation, wiring of starters, etc, over a period of several years was likely to be almost as expensive and more space consuming. While pumped supplies operated without trouble in most cases there was the possibility of pulsations being produced together with head-flow drift in certain applications, as instanced by $\mathrm{Mr}$ Addison in his reference to the main flume and Kaplan turbine supplies. The Authors had information from the N.E.L. at East Kilbride that extreme cases exist where flow fluctuations of some $10 \%$ occur. The pumps at Manchester could be used in conjunction with large air vessels to avoid pulsations but had not been stabilized for head-flow drift. Pump No. 1 and Turbine No. 5 were transferred from the Whitworth Laboratory where they had been installed originally by Professor Gibson many years ago (in connexion with the comment by Dr Silvester, the head- 
power characteristics of this machine were necessary in order to cover the full range of operating conditions on the turbine) and the combination had been found to have very stable characteristics. The pump H.P. was not excessive if the characteristics of turbine No. 5 were to be fully investigated and as with pump No. 2 the wastage of power did not arise since, being variable speed machines, the head was adjusted by altering the rotational speed. There was however a motorized valve on the discharge line and this could be servo-controlled to provide a measure of head-flow drift compensation if necessary. It would be interesting to know if trouble had been experienced from fluctuations in pumped supplies in other laboratories. Presumably there had been no adverse experience at the University of Strathclyde since Dr Barr intended to rely on the multipump system in the new design.

143. The suggestion by Dr McDowell that the use of a few larger ring main pipes, as adopted in the laboratory at Belfast, would have been less expensive may well have produced again the trouble from interference experienced in the old laboratory at Manchester. If one assumed for example an 8 in. main some $150 \mathrm{ft}$ long, designed for a maximum velocity of $6 \mathrm{ft} / \mathrm{s}$ to serve several items of different maximum demand, the friction head loss would be of the order of $3 \mathrm{ft}$. Thus, students taking only small flows would be subjected to a head change of almost $3 \mathrm{ft}$ when the demands from apparatus of larger capacity altered. The rapid closure of valves would also produce pressure surges to the annoyance of interconnected users. The cost of installing several P.V.C. pipes of 2,3 , and 4 in. diameter had been found to be not greatly different from that for installing an 8 in. diameter steel pipe.

144. The method of using a regulated pressure tank devised by Dr Silvester at the University of Western Australia appeared to offer considerable advantages as regards space and cost - an improvement in the stability of head control would enhance the attractiveness of this method. For example, the Authors had had requests in the past for the calibration of meters involving in one case a large orifice plate, the maximum flow accuracy specified being better than $0.2 \%$. This kind of accuracy required controlled conditions not easily achieved but surely to be aimed at in the design of new equipment.

145. Dr Silvester questioned the dimensions of the constant head tanks and the operation of the servo-controlled valves. The dimensions were a function of the control level aimed at and were determined mainly by the need to smooth the 5 cusec inflow through baffling and to enable the larger eddies to degenerate sufficiently before reaching the outlets. Again, the outlets had been adequately spaced to reduce the inter-action pointed out by Mr Kilner, in model tank tests at the University of Capetown. The same considerations applied to both tanks except that the weir length could have been reduced on the high level tank. The Authors felt that the refinements incorporated giving high head stability would be a valued feature of the laboratory in years to come. In an overhead tank an overflow pipe was essential and it had been decided to incorporate simple trough overflow weirs for accurate head control, should the servo-controlled valve not be in operation. In this case the pumps would deliver 5 cusecs to each tank and this could lead to a wastage of power in pumping some of the flow back to the sump via the overflow weirs. The characteristics of the pumps were such that a relatively small increase in head noticeably reduced the flow and with the servo-controlled valve acting the pump power consumption therefore followed more closely the flow demanded from the tank. The pumps were started by simple push button and had required very little attention after the initial commissioning period. Trouble had, however, been experienced with slamming of the non-return valve on the high level supply line and this could be replaced with advantage by a non-recoil type valve.

146. Mr Rydz posed the question of weight against volumetric calibration, particularly in view of the latter being adopted in Professor Francis' laboratory. Basically both methods should give comparable accuracy of calibration provided the required measurements-either volume or weight, and temperature-were made with 
the required accuracy; points of detail arose in favour of one or the other depending on the circumstances. The feature of the laboratory in the Simon Engineering building which dictated the choice to a large extent was the underfloor tank arrangement in conjunction with the main flume discharge deflector gear. Here weighing at floor level at rather greater cost was much more convenient than volume measurement. The volumetric tank in Professor Francis' laboratory was above ground floor level and no complication arose in the accurate measurement of levels. From the cost point of view, large volumetric tanks had to be rigidly constructed to limit deformation under load and corrections for change in temperature might involve the tank as well as the water. The inflow conditions also required care to avoid undue air entrainment.

147. The Authors had considered the feasibility of automatically measuring the inflow to the tank on either a time or weight basis on similar lines to the scheme outlined by Dr Silvester, but came to the conclusion that dynamic and surging effects with a weighbridge might require considerable damping at the expense of sensitivity. They would be interested to know what precautions had been taken by Dr Silvester to reduce the effects of surface waves on the water contacts. The cost of the 15 ton weighbridge at Manchester had amounted to little more than one third of the total cost (under $£ 2000$ ) of the calibration unit including installation (i.e. weighbridge tank, deflector gear, and pump for emptying).

148. The suggestion by Mr Prosser that calibration facilities be provided in special laboratories and more general use be made of secondary standards would provide a saving in space and in initial cost but was not without drawbacks. Firstly, it was generally conceded that calibration in the normal position was desirable for accuracy, and secondly, the thought of sending a range of meters up to say 12 in. diameter with associated piping for periodic recalibration did not sound attractive.

149. The effect on calibration of the large capacity of the flume was queried by Dr McDowell, and the Authors agreed that there was a disadvantage in the time for steady conditions to become established rather than any inherent inaccuracy in the system. The time lag could be greatly reduced by running the flow into a suitably partitioned-off section of the flume near the weigh tank end. Provision had been made for fixing partitions at several points.

150. The Authors noted that the trend of the comments concerning the main flume indicated surprise at the modest dimensions adopted. Compared with the $5 \mathrm{ft} \times 5 \mathrm{ft} \times 300 \mathrm{ft}$ long channel provided at Capetown this was indeed so, but the Authors had designed the unit to suit the length of the laboratory with no possibility of encroaching on neighbouring areas. Likewise the cross section was related to the maximum flow from pump No. 1 which could only provide a mean velocity of about $1 \mathrm{ft} / \mathrm{s}$ with the channel at full depth. The use of this channel for the calibration of miniature propeller meters was not intended for other than low velocity tests requiring relatively short lengths for acceleration and deceleration. It was considered more appropriate to ensure adequate entry conditions to the flume than to increase its length by a few feet as suggested by Dr Silvester.

151. The Authors reported that the sealing of the glass lining of the flume, at first assumed a relatively simple operation by the sub-contractor concerned, led to water creeping between the glass and the butyl rubber backing, and after more than one failure to produce a satisfactory seal, the relining of the flume was now under consideration.

152. The reason for the failure of the interstitial mortar in the tests carried out on the terrazo was believed by the Authors to be primarily due, not to a high water/ cement rate as suggested by Professor Naylor, but to the fact that terrazo specialists were careful to grind terrazo surfaces while 'green' after two to three days' curing otherwise their grinding equipment was adversely affected. Thus the interstitial mortar at the surface contained some of the slurry formed during grinding. Any grinding process applied to concrete mixtures under these conditions was unlikely 
to be satisfactory as a flume lining. Armour plate glass was considered for the base but this was not advised by the glass manufacturer mainly on the grounds of the liability to craze should a heavy tool be accidently dropped on it.

153. The Authors agreed with Mr Seddon that the functional requirements of hydraulic establishments such as the Hydraulic Research Station, the N.E.L. and the B.H.R.A. were in many respects different from those of university laboratories, but common interests in basic research formed an encouraging ground for closer cooperation in future work. Their respective advantages also differed in many respects as, for example, on the one hand the scale of the models of such varying type which could be handled at Wallingford balanced on the other by the greater freedom of university lecturers to concentrate their activities on problems of their own choice.

154. The tilting sand flume at Manchester about which Mr Seddon enquired had no provision at present for recirculating sediment but a variable feed rate could be introduced at the inlet end and a collector was provided at the outlet end for weighing.

155. In connexion with the main sump, the Authors could not agree that the area and volume were great. Taking the figures quoted by Dr Silvester as sufficiently accurate, then with the flume full, the sump depth would drop to $3 \mathrm{ft}$ which would be just sufficient to provide an adequate suction depth for the $12 \mathrm{in}$. strainers of the service pumps and for the suction of the $10 \mathrm{in}$. axial flow pump. Any saving in cost by area reduction would be offset by the need to construct deeper sections in several sump locations. Furthermore, a reduction in surface area would be undesirable for other reasons. The flume could be in use while pump or reaction turbine tests were being carried out and a continual variation in sump depth would affect the operational head for these machines. The sump had also been designed so that there would be access over a wide area for pumping up or returning water to the sump (essential 7(b)).

156. The Authors had found from experience with the filtration plant that salts would accumulate with continuous dosing as indicated by Professor Naylor but the effect had been minimized by using sump water to backwash the filters and drawing town water to make up the loss each day. Otherwise a change of water each year appeared satisfactory. The Authors doubted very much whether Manchester Corporation Water Works Department would be greatly in favour of the suggestion by $\mathrm{Mr}$ Prosser that water being cheap, filtration could be dispensed with and the system recharged frequently. The supply position varied from one district to another but became progressively more difficult each year. The quality also varied and in Manchester $p H$ correction was desirable.

157. The Authors had not experienced any corrosion in pipes of the type that had occurred at Belfast as described by Professor Naylor and Dr McDowell, since of course P.V.C. or bitumen lined pipes were used. The pumps, large valves, and air vessels had been treated with Detel Red and as in the past it was intended to re-paint the air vessels when opened for the necessary two-yearly insurance inspections. The maintenance of valves and pumps, etc, was a much more formidable task and the Authors had still to draw up a comprehensive maintenance rota for the laboratory including Detel re-treatment, depending on the availability of service staff.

158. In response to the many requests for information on the operation and running of the laboratory, the Authors pointed out that the intake of students was increasing each year, currently being about two-thirds of the designed maximum. The Authors were responsible for lectures and laboratory courses in hydraulics but another member of staff would be added to the hydraulics group for next session. One senior technician and one technician were responsible for the maintenance, the general running of the laboratory, and for the construction and installation of research apparatus. There was a central workshop serving the civil, mechanical, and nuclear engineering departments and this workshop undertook the construction of major equipment. General cleaning and labour were also available.

159. The noise problem experienced by $\mathrm{Mr} \mathrm{Simm}$ in his laboratory could be a real annoyance particularly to research students located for long periods in the 
laboratory itself. The service pumps had been the chief source of this trouble in the new laboratory and it had not been anticipated as they were located in the sub-basement. The access stairway was an open one and the possibility of fitting a closing panel was under consideration.

160. During most of the teaching session, the laboratory had operated on three days per week with groups of up to 18 students, two per experiment, in rotation for second and third year classes. The work of supervision was eased by research students giving assistance as demonstrators in the laboratory. The Authors agreed with Mr Kenn that in view of the tendency noted previously to reduce the number of set experiments there was need to make a careful selection. This particular laboratory catered for both civil and mechanical engineering students which accounted for the number of turbine and pump sets. They also suggested that some advantage could be derived from say one group comparing the characteristics obtained from a centrifugal pump with those obtained by another group testing an axial flow pump. Some of the pumps had multiple functions for particular reasons and for example the large pump set at No. 2 which was mentioned by Dr Silvester was partly donated by a local firm and was intended for the carrying out of extensive pipe friction tests on up to 6 in. diameter pipes at relatively high Reynolds numbers with graded roughnesses. At a later stage in the design it was decided to interconnect the discharge line from this pump to have a reserve supply to both the flume and the high level tank. Later still instrumentation was added to facilitate the testing of the pump characteristics.

161. Research students and undergraduate students on projects had access to the laboratory at any time while the Simon Engineering building was open. There were no lecture or tutorial rooms allocated specifically to hydraulics and use was made of the accommodation provided generally in the building. The Authors were doubtful whether the kind of scheme outlined by Mr Addison as intended for the Giza building could be successfully introduced at Manchester; timetable difficulties themselves would be formidable.

162. The Authors were unable to give an overall cost for the laboratory as asked for by Dr Silvester, since work which was done under the direction of the Architect including the sump and main flume was inseparable from the building cost; other equipment was made in the departmental workshop and apparatus from the old laboratory was serviced and transferred. They were able to provide the following prices for some of the main items of the installation:

Two overhead tanks (supports, baffles, sparge pipes, etc.)

Bitumen lined steel piping ( 8 in. to 12 in. diameter including supports) P.V.C. piping (6 in. dia. and under)

Valves (including one 12 in. electrically operated)

Turbines Nos 7 and 10

Pumps Nos 2, 6, and 8

Service Pumps Nos 38 and 39 (including servo valves, etc.) 3288

Pressure Vessel No. 3

Filtration Plant

2974

Main Calibration Unit (weighbridge, deflector, tank, etc.)

1848

163. The Authors hoped that the further information supplied in response to the comments of the contributors would be found adequate. They had themselves found the discussion most instructive and by revealing the differing viewpoints in regard to the most satisfactory methods available-depending on the circumstances imposed upon the designers--for achieving the features listed as essential, it would add greatly to the value of the Paper. The designers of future laboratories would no doubt benefit accordingly. 


\section{REFERENCES}

2. Addison H. Instruction and research in hydraulic laboratories. Proc. Instn mech. Engrs, 1952-53, 1B, (9), 401.

3. KeNN M. J. Laboratory teaching in fluid mechanics. Engineering, 1963, 196, $596-97$.

4. Silvester R. Characteristics and applications of the water-jet pump. $L a$ houille blanche, vol. 16, 1961, p. 451.

5. Silvester R. and Mills J. Timing unit for measuring discharge rate. Engineering, 1962, 194, 657.

6. Silyester R. Triple purpose hydraulics laboratory. Engineering, 1962, 193, 477.

7. Hellstrom B. and Reinius E. The hydraulic laboratory at, the Royal Institute of Technology, Stockholm. Trans. Royal Inst. Tech., Stockholm, No. 219, 1963.

8. Glenfield Group hydraulics Iaboratory. Glenfield Gazette, 1961, 32, (3, Dec.) 17-27. 